\title{
ANTHROPIC RISK ASSESSMENT ON BIODIVERSITY
}

\author{
Piragnolo M. ${ }^{\mathrm{a}}$, Pirotti F. ${ }^{\mathrm{a}}$, Vettore A. ${ }^{\mathrm{a}}$, Salogni G. ${ }^{\mathrm{b}}$ \\ ${ }^{a}$ CIRGEO, Interdepartmental Research Center on Cartography, Photogrammetry, Remote Sensing and GIS University of Padua, \\ viale dell’Università, 1635020 Legnaro - mar_pir@yahoo.it, (francesco.pirotti,antonio.vettore)@unipd.it \\ ${ }^{\mathrm{b}}$ Veneto Region, Commission's Coordination Project Unit, via Cesco Baseggio 530170 Mestre (VE) - \\ gianluca.salogni@regione.veneto.it
}

KEY WORDS: Hazards, Impact analysis, Ecosystem, Environment, Spatial Infrastructures, Temporal, Decision support

\begin{abstract}
:
This paper presents a methodology for risk assessment of anthropic activities on habitats and species. The method has been developed for Veneto Region, in order to simplify and improve the quality of EIA procedure (VINCA). Habitats and species, animals and plants, are protected by European Directive 92/43/EEC and 2009/147/EC but they are subject at hazard due to pollution produced by human activities. Biodiversity risks may conduct to deterioration and disturbance in ecological niches, with consequence of loss of biodiversity. Ecological risk assessment applied on Natura 2000 network, is needed to best practice of management and monitoring of environment and natural resources. Threats, pressure and activities, stress and indicators may be managed by geodatabase and analysed using GIS technology. The method used is the classic risk assessment in ecological context, and it defines the natural hazard as influence, element of risk as interference and vulnerability. Also it defines a new parameter called pressure. It uses risk matrix for the risk analysis on spatial and temporal scale. The methodology is qualitative and applies the precautionary principle in environmental assessment. The final product is a matrix which excludes the risk and could find application in the development of a territorial information system.
\end{abstract}

\section{INTRODUTION}

The goal of this work is to propose a new experimental methodology for ecological and environmental risk assessment. This methodology is developed for public administration of Regione Veneto. Habitats and species are protected by European Directive 92/43/EEC and 2009/147/EC on the conservation of natural habitats and of wild fauna and flora and wild birds; they are described by Commission Implementing Decision 2011/484/EU 2011 by standard data form. In this study we want assess plane, project and action to check that there aren't significant negative impacts on habitats and species of the Natura 2000 network. The Natura 2000 network is influenced by several factors, some of natural source and many form anthropic source, that are originated by the activities conducted in the territory. They are called threat, pressure and activities with impact on the site (Commission Implementing Decision 2011/484/EU 2011) and listed in final form in EIONET's website (EIONET, 2013). Each of them is analysed using an indicator; the measure of indicator is related to geodatabase (Salogni et al., 2012). The measures for the conservation of habitats and species are spatial limited in the Special Areas of Conservation (SAC), but other measures may need implemented outside, if an external events may have impact inside the SAC. The measures should avoid the deterioration of habitat and disturbance of species. Deterioration is a physical degradation affecting habitat and must be avoided. Disturbance concerns the species. It's often limited and it has an intensity, duration and frequency and it could be significant (have an impact) for conservation status of a species (European Communities, 2000). It occurs in spatial or temporal scale. The protection of valuable natural resources require a better understanding of how the scale of the environmental hazard affects ecological processes and over what scales the effects should be monitored and examined (Hunsaker et al., 1990). The assessment of plans and projects significantly affecting Natura 2000 has been designed to be compatible with general Environmental impact assessment (EIA) procedures and can be easily integrated into Strategic impact assessment (SEA) (European Communities, 2002). Ecological and environmental impact assessments needs multidisciplinary skills and databases; for examples they need information about the environment, soil, geomorphology, ecology, toxicology, chemistry and so on. Sometime the databases are accessible and good quality, other times they are partial, incomplete or not accessible. In this case we suggest to apply the precautionary principle, because the decision-makers are faced with the dilemma to balance freedom and rights of individual with need to reduce the risk of adverse effects of the environment, human, animal or plant health. It should be considered within a structured approach to analysis of risk (Commission of the European Communities, 2000). It is important to take uncertainty about anything that matters as the starting point for risk management purposes (Chapman et al., 2003). Many studies were conducted to assess the risk for environment, ecosystem. U.S. EPA use the term Ecological risk assessment (ERA) to define a process that evaluates the likelihood that adverse ecological effects may occur or are occurring as a result of exposure to one or more "stressors" and evaluate human-induced changes that are considered undesirable (U.S. EPA., 1998). The term stressor is used here to describe any chemical, physical, or biological entity that can induce adverse effects on individuals, populations, communities, or ecosystems (U. S. EPA, 1992; U.S. EPA, 2013). It's crucial to define the ecosystem, know the species and population or community at risk (Iscan, 2004). Habitat and species may be vulnerable to threat, pressure and activities. Vulnerability it's an intrinsic properties of something resulting in susceptibility to a risk source that can lead to an event with a consequence (ISO, 2009). In this paper we propose a qualitative method for risk assessment based on matrix, to prevent the risk for habitat and species. The format of the matrix and the definitions applied to it depend on the context in which it is used and it is important that an appropriate design is used for the circumstances (ISO/IEC, 2009). Matrix risk was applied in many contest and generic matrix was used with a wide variety of project types, pollution (Murray et al., 2011). In a matrix likelihood and consequence are estimated and then brought 
together to estimate risk (MacEwan et al., 2004). When we developed this methodology we had need to answer at some question: what are the object of analysis, where are they placed in the territory, what are threat, pressure and activities, where are they placed, when they produce significant negative impacts. Modelling different types of habitats requires the identification of a set of environmental variables which are related to the spatial distribution of animals at each scale (Bellier et al., 2010). The effect of a disturbance depends by the structure of system, by the scale at which the system is observed (Rykiel, 1985) and to ensure survival of a particular species, the size of the patch may be less important than their persistence over the time (Fahrig, 1992). Also a human processes operate in a temporal context, a spatial context, or both (Agarwal et al.,2000). When we approach the problem we dived in two parts: spatial scale and temporal scale. Spatial scale describes where the habitats are placed, their areas, the degree of conservation and fragmentation, which are the relations from the patches and the effect areas of threat, pressure and activities. Temporal scale describes when threat, pressure and activities occur, their frequency, duration but also when ecosystem is more vulnerable for example considering the phenology. They may be managed using geodatabase and GIS technology. All Uncertainties related to temporal scale and spatial scale are important and they are combined in the final risk assessment (Hunsaker et al., 1990). This method may be applied in the building of GIS as support decision system in order to simplify EIA procedure (Piragnolo, 2012).

\section{METHODOLOGY}

\subsection{Anthropic risk assessment on biodiversity.}

Risk can be defined like the product of the likelihood that something will happen and the consequence suffered if it happens (MacEwan et al., 2004). Risk means the expected number of live lost, person injured, damage property or disruption of economic activity due to a particular natural phenomenon and it is the product of specific risk (Rs) and element of risk (E) (Varens, 1984). It can be stated mathematically as

$\mathrm{Rt}=(\mathrm{E})(\mathrm{Rs})=(\mathrm{E})(\mathrm{H} \times \mathrm{V})$

where:

Natural Hazard $(\mathrm{H})$ means the probability of occurrence within a specified period of time and within a given are potentially damaging phenomenon.

Vulnerability (V) means the degree of loss a given element or set of element at risk resulting form occurrence of a natural phenomenon of a given magnitude.

Element of risk (E) means the population properties, economic activities etc. at risk given area.

In ecological contest we define risk as the product of pressure (P) and vulnerability of habitat and species (V)

$\mathrm{R}=(\mathrm{P}) *(\mathrm{~V})$

where:

Pressure $(\mathrm{P})$ means the probability that threat, pressure or activities may have influence significant negative, in a spatial and temporal context, on habitat or species.

Vulnerability (V) means the intrinsic properties of habitat and species resulting in susceptibility to a specific threat, pressure or activities with significant negative impact.

$\mathrm{R}=(\mathrm{V})(\mathrm{IN} \times \mathrm{IT})$

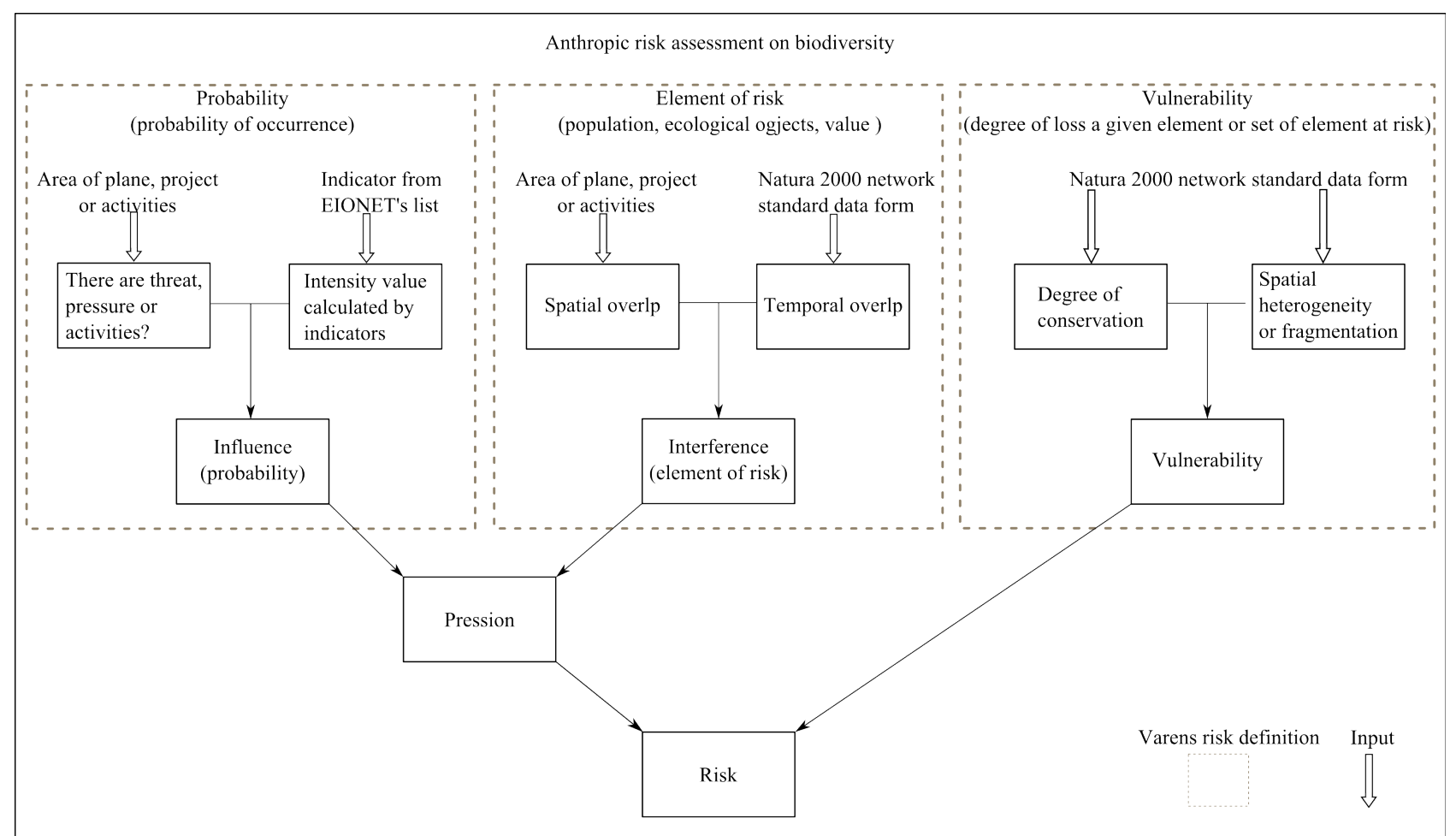

Figure 1. Anthropic risk assessment flow chart 
Influence (IN) means the intensity of threat, pressure or activities that occur on habitat

Interference (IT) means the spatial and temporal overlap of threat, pressure or activities with habitat and species

A flow chart describes the steps of the analysis (Figure 1)

\subsection{Step 1. Verify the risk assessment.}

The first step of this methodology is to verify if, according with legislation, the plane, project and action need to be assessed. If the answer is negative, the assessment ends. If the answer is positive we go to the next step.

\subsection{Step 2. Identification of the pressures and threats.}

The plane, project and action need to be assessed to identify the pressures and threats. The risk assessment is based on specific threat, pressure and activities that could have significant negative impact (Commission Implementing Decision 2011/484/EU, 2011). Threat, pressure and activities are formed by two elements. The first element is the local component. It describe the object in the real world; for example considering the structure of a factory; the local components are: the structure, the road that connect the plants, the service areas etc. They are fixed and they have a clear localization. The second one is the pollution. It's formed by many types of pollutants for example the emission of the plant, the noise, the drains etc. They are variable in space and time. We need to identify specify and clearly each threat, pressure and activities, then we go to the next step of analysis.

\subsection{Step 3. Assessment of the probability (Influence).}

In this step we assess if the threat, pressure and activities exists in the area, polygon or grid of analysis. If it isn't exist the analysis stops. If it exists we apply the precautionary principle, and the probability of occurrence of event is always $100 \%$ and it always occurs. Now we need to calculate the specific indicators; we use a list created in accordance with standard data form by Commission Implementing Decision 2011/484/EU, 2011. Then we reclassify the indicator in three qualitative class, low, mid and high, at which we assign 1, 2 and 3 values (Figure 2).

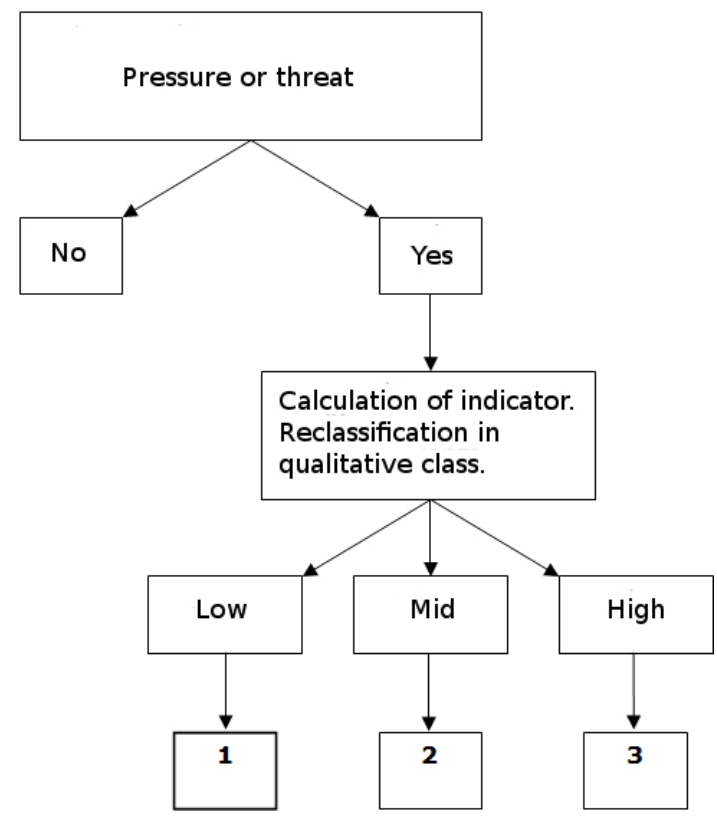

Figure 2. Assessment of the influence

\subsection{Step 4. Elements of risk (Interference).}

In this step we assess the spatial and temporal interference of the threat, pressure and activities with habitat and species. They may haven't with habitat and species, for example if the specie is seasonal. With spatial assessment we analyse if threat, pressure and activities are confined in sector or area where there aren't habitat or species. When we found a spatial overlap we do a temporal assessment. If it isn't verify the process stops. If there is a temporal overlap, we assign the value 1 in case there is only the presence of habitat and we assign the value 2 in case there are both habitat and species (Figure 3)

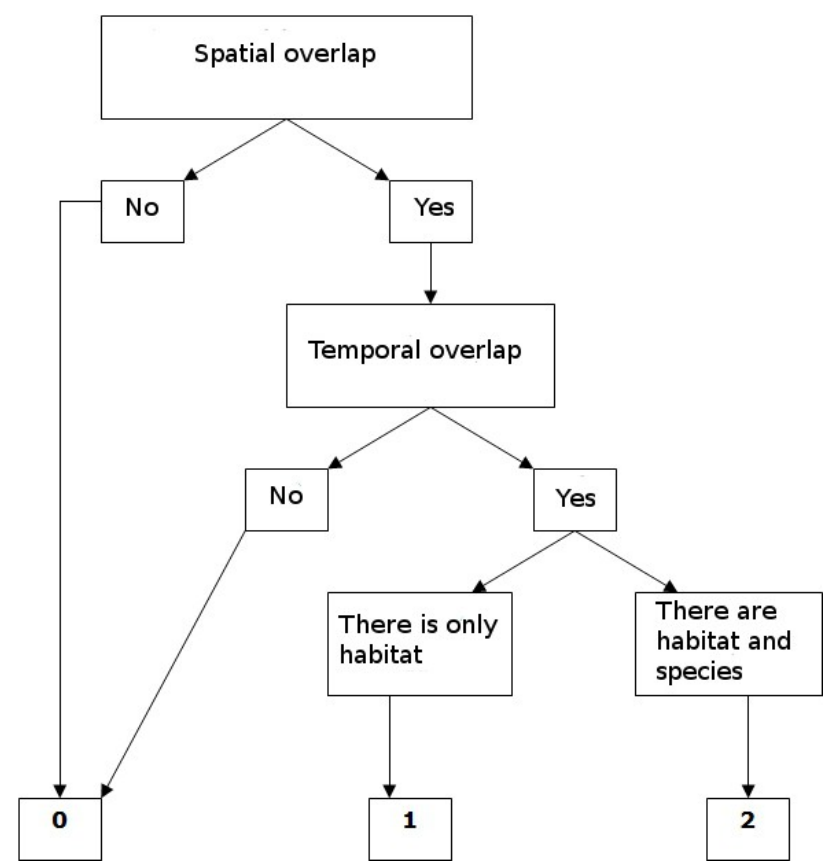

Figure 3. Flow chat for spatial and temporal interference

\subsection{Step 5. Pressure assessment.}

We define the pressure as the combination of probability and risk elements; this means, that we assess the degree of influence of pressure and threat and we combine with the degree of the interference with habitat and species. We use a matrix (Table Table 1) that assign value between 0 and 3 using the precautionary principle. In $\mathrm{X}$ axis there is the influence and in $\mathrm{Y}$ axis the interference. If there is only the habitat of species (value of influence 1) and the species isn't identified, the precautionary principle assign at pressure the same value of the probability (intensity). If there are both habitat and species (value of influence 2) the matrix assign at the pressure the maximum value of probability that is 3 . There is only one case in which the matrix assigns value 0 , and it is when there aren't spatial and temporal overlap between pressure or threat and habitat or species; we don't need to know their value but only their overlap. In this case the procedure stops and we have verify that there aren't significant negative impact. When we verify an effect, we must assess the single threat, pressure and activities. 


\begin{tabular}{|c|c|c|c|c|}
\hline & \multicolumn{4}{|c|}{ Influence } \\
\hline & & 1 & 2 & 3 \\
\hline \multirow{3}{*}{ 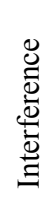 } & 0 & 0 & 0 & 0 \\
\hline & 1 & 1 & 2 & 3 \\
\hline & 2 & 3 & 3 & 3 \\
\hline
\end{tabular}

Table 1. Matrix of pressure

\subsection{Step 6. Assessment of vulnerability.}

Vulnerability is intrinsic properties of something resulting in susceptibility to a risk source that can lead to an event with a consequence (ISO, 2009). In our context this means the sensibility to the threat, pressure and activities and it depends by biological and ecological properties. The analysis of vulnerability is made using Natura 2000 standard data form, that describes conservation of habitat and isolation of species. For the conservation the codes of standard data form are A, B, $\mathrm{C}$ where $\mathrm{A}$ is excellent and $\mathrm{C}$ limited conservation. For isolation the codes of standard data form are A, B, C where A is an isolated population and $\mathrm{C}$ is a species not isolated and placed in a wide range of territory. The conservation code is combined with isolation one and the result is reclassified in six intermediate classes. Then the six classes are reclassified in three classes with value of 1,2 and 3 . For example a conservation's value of habitat A means it has a good conservation. The isolation's value of specie $\mathrm{C}$ means it is isolated and vulnerable. This produce a value intermediate 4 because the habitat is good but the specie occupy isolated patches. It's more sensible to anthropic disturbance, climate fluctuations, possible epidemics etc. The final value is 2 and it meaning we should have more attention to protect it (Figure 4).

\subsection{Step 7. Risk assessment.}

The risk is assess using a matrix that multiply the pressure and vulnerability values (see table 2 below).

\begin{tabular}{|c|c|c|c|c|}
\hline & \multicolumn{4}{|c|}{ Vulnerability } \\
\hline & & 1 & 2 & 3 \\
\hline \multirow{3}{*}{ 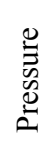 } & 1 & 1 & 2 & 3 \\
\hline & 2 & 2 & 4 & 6 \\
\hline & 3 & 3 & 6 & 9 \\
\hline
\end{tabular}

Table 2. Matrix of risk

This table summarize the precautionary principle with the risk assessment. In order to protect habitat and species it's simple to notice that the suitability of area to the presence of a particular specie is sufficient to produce probability risk (low). The matrix can be interpreted using the next table that describes the action to taken in case of risk. (Table 3 ).

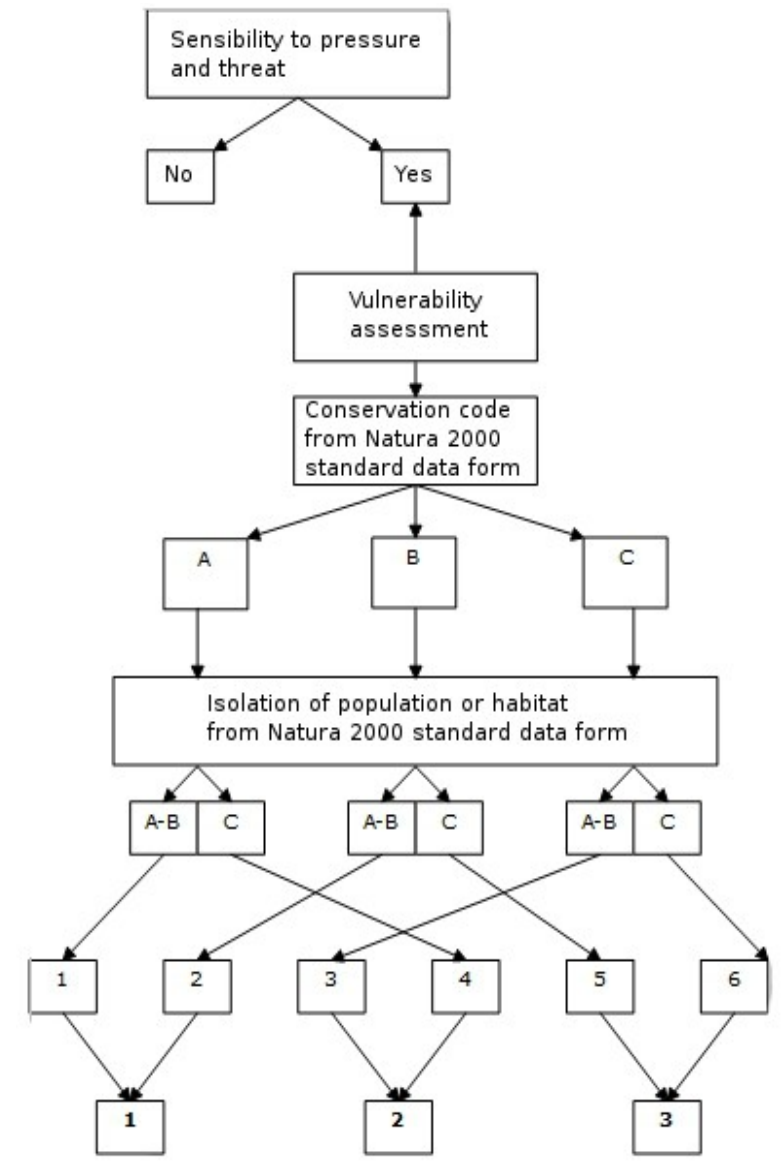

Figure 4. Assessment of vulnerability

\begin{tabular}{|c|c|c|}
\hline Value & Risk & Action \\
\hline 0 & Null & Monitoring plan \\
\hline 1 & $\begin{array}{l}\text { Low - Situation } \\
\text { potentially stable }\end{array}$ & $\begin{array}{l}\text { Monitoring plan - Planning } \\
\text { actions in occurrence of } \\
\text { increased risk }\end{array}$ \\
\hline 2 & $\begin{array}{l}\text { Mid - Situation } \\
\text { potentially unstable }\end{array}$ & $\begin{array}{l}\text { Monitoring plan (high level of } \\
\text { monitoring) - Planning actions } \\
\text { in occurrence of increased risk }\end{array}$ \\
\hline $3-4$ & $\begin{array}{l}\text { High - Situation } \\
\text { potentially serious }\end{array}$ & $\begin{array}{l}\text { Monitoring plan (high level of } \\
\text { monitoring) - Immediate } \\
\text { regulations and action of active } \\
\text { management }\end{array}$ \\
\hline & $\begin{array}{l}\text { Very high - situation } \\
\text { potentially critic }\end{array}$ & $\begin{array}{l}\text { Monitoring plan (high level of } \\
\text { monitoring) - Urgent } \\
\text { regulations and action of active } \\
\text { management }\end{array}$ \\
\hline 9 & $\begin{array}{l}\text { Extreme- situation } \\
\text { potentially } \\
\text { irreversible }\end{array}$ & $\begin{array}{l}\text { Monitoring plan (high level of } \\
\text { monitoring) - Priority } \\
\text { regulations and action of active } \\
\text { management }\end{array}$ \\
\hline
\end{tabular}

Table 3. Table for interpretation of risk; plan and action in occurrence of risk by public administration. 


\section{CONCLUSION}

This methodology proposed in this paper is in experimental phase. It is a prototype and need to be tested. Habitat and species, protected by European legislation, are vulnerable element of environment. The need to exclude risk, produced by anthropic activities, has lead to define a procedure that include the precautionary principle as important part of the method. Threat pressure and activities, listed by European legislation, are the hazard element that we analysed. They have a spatial and temporal components that are assessed using matrix risk. From the classic risk analysis, we have defined a new component called pressure, that is probability that threat, pressure or activities may have influence significant negative, in a spatial and temporal context, on habitat or species. The method needs to know the spatial area and localization of plane project and action in order to assess spatial and temporal overlap with habitat and species. It can easily be done using a GIS software and geodatabase. It's important to note that the threat, pressure and activities may exist but if they don't overlap with habitat and species, they don't produce risk. When a single threat pressure and activities, also with low intensity, is identified, the risk will occurs. The method is developed for the public administration of Veneto Region with the scope to exclude significant negative impact, in order to simplify and improve the quality of European EIA, implemented in the Italian legislation as VINCA procedure. Also a professional can use this instrument to simplify and improve his work. An added value can be to implement a collaborative environment like it was done in Pirotti et al. (2011). The future development may be the building of a GIS as support decision system. This would automatize exclusion significant negative impact on habitat and specie, activate online the administrative procedures, manage specific cartography, and assess the synergy effects of pollutants.

\section{REFERENCE}

Agarwal, C., Green, G. L., Grove, M., Evans, T., Schweik, C., 2000. A Review and Assessment of Land-Use Change Models Dynamics of Space, Time, and Human Choice. Center for the Study of Institutions Population, and Environmental Change, Indiana.

Bellier, E., Certain, G., Planque, B., Monestiez, P., Bretagnolle, V., 2010. Modelling habitat selection at multiple scales with multivariate geostatistics: an application to seabirds in open sea. Oikos 119, pp. 988-999.

Chapman, C., Ward S., 2003. Project Risk Management Processes, Techniques and Insights. John Wiley \& Sons Ltd, Chichester, pp 6.

Commission of the European Communities, 2000. Communication from the Commission on the precautionary principle. Brussels.

Commission Implementing Decision 2011/484/EU concerning a site information format for Natura 2000 sites, 2011. Official Journal of the European Union, L 198/39.

Council Directive 92/43/EEC on the conservation of natural habitats and of wild fauna and flora, 1992. Official Journal of the European Union, L. 206/7.
Directive 2009/147/EC of the European Parliament and of the Council on the conservation of wild birds, 2010. Official Journal of the European Union, L. 20/7.

EIONET 2013. Reference list Threats, Pressures and Activities (final version).

http://bd.eionet.europa.eu/activities/Natura_2000/reference po rtal (accessed 05 Feb. 2013)

European Communities, 2002. Assessment of plans and projects significantly affecting Natura 2000 sites Methodological guidance on the provisions of Article 6(3) and (4) of the Habitats Directive 92/43/EEC. Luxembourg, pp. 12

European Communities, 2000. Managing Natura 2000 sites. The provisions of Article 6 of the 'Habitats' Directive 92/43/EEC. Belgium, pp 24-29.

Fahrig, L., 1992. Relative importance of spatial and temporal scales in patcher environment. Theoretical Population biology, 41(3), pp. 300-314.

Harrington, J. M., Canter, W. L., 1998. Planning environmental monitoring programs within the environmental impact assessment process.. International Journal Environmental Sudies, 55, pp 305-331.

Hunsaker, C.T., Graham, R. L., Suter, G.W , O'neill, R.V., Barnthouse, L.W., Gardner, R.H ., 1990. Assessing Ecological Risk on a Regional Scale. In: Environmental Management, Vol. 14, No. 3, pp. 325-332, New York.

Iscan, M., 2004. Hazard identification for contaminants. Toxicology, 205 (2004), pp. 195-99.

ISO, 2009. Guide 73:2009 Risk management - Vocabulary. Switzerland.

ISO/IEC, 2009. 31010:2009 Risk management - Risk assessment techniques.

MacEwan, R., Bluml, M., McNeill, J., Reynar, K., 2004. Land use impact modelling for native biodiversity risk. The State of Victoria, Department of Sustainability and Environment.

Murray, S. L., Grantham, K., B. Damle, S. B, 2011. Development of a Generic Risk Matrix to Manage Project Risks. Journal of Industrial and Systems Engineering, 5(1), pp. $35-51$.

Piragnolo, M., 2012. Sistema di supporto per la valutazione di impatti sulla biodiversità. Master thesis, IUAV University, Venice.

Pirotti, F., Guarnieri, A., Vettore, A. 2011. Collaborative WebGIS design: a case study for road risk analysis and monitoring. Transactions in GIS, 15(2), pp. 213-226.

Rykiel, E.J., 1985. Towards a definition of ecological disturbance. Australian Journal of Ecology, 10, pp.361-365.

Salogni, G., Costa M., de Franco, F., Dorosencu, A., Kamburov, I., Ziglio, S., Loreggian, M., Gussev, Ch., Tzonev, R., 2012. BE-Natur: BEtter management and implementation of NATURa 2000 sites. WP3: Transnational joint strategy and tools for the better management and implementation of Natura 
The International Archives of the Photogrammetry, Remote Sensing and Spatial Information Sciences, Volume XL-5/W3, 2013 The Role of Geomatics in Hydrogeological Risk, 27 - 28 February 2013, Padua, Italy

2000 sites. Joint Transnational Action Plan on Coastal Sand Dunes.

U.S. EPA 1992. Framework for ecological risk assessments. Risk Assessment Forum. U.S. Environmental Protection Agency, Washington.

U.S. EPA, 1998. Guidelines for Ecological Risk Assessment. U.S. Environmental Protection Agency, Washington.

U.S. EPA, 2013. EPA Risk Assessment Basic Information. http://www.epa.gov/risk/basicinformation.htm (accessed 05 Feb. 2013).

Varens, J., 1984. Landslide hazard zonation: a review of principles and practice. United Nations Educational. Darantiere, Quetigny, pp. 10. 